\title{
TRPV1 Receptors Contribute to Paclitaxel-Induced c-Fos Expression in Spinal Cord Dorsal Horn Neurons
}

\author{
N. KALYNOVSKA ${ }^{1,2}$, P. ADAMEK ${ }^{1}$, J. PALECEK ${ }^{1}$ \\ ${ }^{1}$ Department of Functional Morphology, Institute of Physiology of the Czech Academy of Sciences, \\ Prague, Czech Republic, ${ }^{2}$ Faculty of Sciences, Charles University, Prague, Czech Republic
}

Received February 8, 2017

Accepted March 17, 2017

\begin{abstract}
Summary
Transient receptor potential vanilloid type 1 (TRPV1) receptors are important in the development of different pathological chronic pain states. Here we examined the role of spinal cord TRPV1 receptors in the mechanisms leading to activation of dorsal horn neurons after paclitaxel (PAC) treatment. PAC is a widely used chemotherapeutic drug that often leads to development of painful neuropathy. Immunohistochemical analysis of c-Fos protein expression in dorsal horn neurons was used as a marker of neuronal activation. Rat spinal cord slices were processed for in vitro incubation with PAC (100 nM) and TRPV1 receptor antagonists (SB366791 and AMG9810; $10 \mu \mathrm{M}$ ). PAC treatment induced significant upregulation of c-Fos nuclear expression in superficial dorsal horn neurons that was diminished by TRPV1 receptor antagonists pre-incubation. These results further substantiated the role of spinal TRPV1 receptors in the development of paclitaxel-induced neuropathic pain and contribute to better understanding of the pathological mechanisms involved.
\end{abstract}

\section{Key words}

c-Fos • Paclitaxel • TRPV1 • Neuropathy • Spinal cord

\section{Corresponding author}

J. Palecek, Department of Functional Morphology, Institute of Physiology, Czech Academy of Sciences, Videnska 1083, 14220 Prague 4, Czech Republic. Fax: +420 241062 488. E-mail: palecek@biomed.cas.cz

\section{Introduction}

Paclitaxel (PAC) induced peripheral neuropathy (PIPN) and neuropathic pain syndromes are often a dose limiting adverse side effects of PAC anticancer therapy. For now, there is no effective treatment available, as the underlying cause of this PIPN remains poorly understood while many possible mechanisms were indicated (Boyette-Davis et al. 2015). Transient receptor potential vanilloid type 1 (TRPV1) receptors are expressed in the dorsal root ganglia (DRG) neurons and are known to act as integrators of noxious stimuli in the periphery (Nagy et al. 2014, Cui et al. 2016) and as modulators of nociceptive signaling in the spinal cord (Spicarova et al. 2014b). Recent studies suggested an active role of TRPV1 receptors in the pathological mechanisms of PIPN both in the peripheral and central nervous systems (Hara et al. 2013, Li et al. 2015). c-Fos is a small nuclear protein, translated from proto-oncogene c-Fos that has been widely used as a marker for activation of nociceptive neurons in the superficial laminae of spinal cord dorsal horn (Hunt et al. 1987). After in vivo paclitaxel treatment, low levels of PAC penetrates to the central nervous system (Yan et al. 2015). Here we tested hypothesis that application of low concentration PAC $(100 \mathrm{nM})$ treatment would induce c-Fos expression in dorsal horn neurons that would be dependent on TRPV1 receptors activation. Immunohistochemical analysis was used to determine c-Fos expression in spinal cord slices incubated with PAC with and without the presence of TRPV1 antagonists SB366791 or AMG9810.

All experiments were approved by the Institutional Animal Care and Use committee and were carried out in accordance with the guidelines of the International Association for the Study of Pain and EU Directive 2010/63/EU for animal experiments. All efforts 
were made to minimize animal suffering and to reduce the number of animals used. Acute spinal cord slices were prepared altogether from 15 juvenile male Wistar rats $\sim \mathrm{P} 21$, as previously described (Spicarova et al. 2011, Spicarova et al. 2014a). The rats were deeply anesthetized (Forane ${ }^{\circledR}$, Abb Vie Czech Republic), lumbar spinal cords were removed and immersed in oxygenated ice-cold dissection solution containing (in $\mathrm{mM}): \quad 95 \mathrm{NaCl}, \quad 1.8 \mathrm{KCl}, \quad 7 \mathrm{MgSO}_{4}, \quad 0.5 \mathrm{CaCl}_{2}$, $1.2 \mathrm{KH}_{2} \mathrm{PO}_{4}, \quad 26 \mathrm{NaHCO}_{3}, \quad 25 \mathrm{D}$-glucose, 50 sucrose. Acute transverse slices $350 \mu \mathrm{m}$ thick were cut (Leica, VT $1200 \mathrm{~S}$, Germany) from the lumbar segments L4-L6, incubated for $30 \mathrm{~min}$ at $35^{\circ} \mathrm{C}$ and then stored in incubating solution (in $\mathrm{mM}: 127 \mathrm{NaCl}, 1.8 \mathrm{KCl}$, $1.2 \mathrm{KH}_{2} \mathrm{PO}_{4}, \quad 2.4 \mathrm{CaCl}_{2}, \quad 1.3 \mathrm{MgSO}_{4}, \quad 26 \mathrm{NaHCO}_{3}$, $25 \mathrm{D}$-glucose) at room temperature to recover for $1 \mathrm{~h}$ before the experiment. Alternating slices were assigned to the groups with different incubation protocol: paclitaxel (Sigma-Aldrich, PAC group, $100 \mathrm{nM}, 60 \mathrm{~min}$ ); TRPV1 antagonists only (SB366791 (Tocris Bioscience, UK), AMG9810 (Sigma-Aldrich), $10 \mu \mathrm{M}, 70 \mathrm{~min}$, groups $\mathrm{SB}$ and $\mathrm{AMG}$ respectively); TRPV1 antagonists $(10 \mu \mathrm{M})$ for 10 min with added PAC (100 nM, $60 \mathrm{~min})(\mathrm{SB}+\mathrm{PAC}$ or AMG + PAC groups). A control group of slices was incubated with vehicle (DMSO, $2 \%, 70 \mathrm{~min}$, CTRL group). Incubation solution was constantly saturated with $\begin{array}{lllll}95 & \mathrm{O}_{2} \text { and } & 5 \% & \mathrm{CO}_{2} \text {. Slices were fixed in } 4 \%\end{array}$ paraformaldehyde, cryoprotected and cut in cryostat to 15-20 sections $16 \mu \mathrm{m}$ thick from the middle portion of the slices. These sections were then immunohistochemically processed for detection of c-Fos expression. Briefly, sections were blocked with $3 \%$ normal donkey serum, incubated overnight at $4{ }^{\circ} \mathrm{C}$ with anti-c-Fos (anti-rabbit, 1:2,000; Santa Cruz, USA) antibody in $1 \%$ NDS with $0.3 \%$ Triton X-100. For $\mathrm{SABC}$ staining, the sections were incubated for $2 \mathrm{~h}$ with biotinylated secondary antibody (1:400) and $2 \mathrm{~h}$ with peroxidase-conjugated streptavidin (1:400; Jackson ImmunoReasearch, USA). Finally, the reaction product was visualized with $1.85 \mathrm{mM} \mathrm{DAB} / 0.003 \%$ hydrogen peroxide in PBS for 2-5 min (Sigma-Aldrich, USA). Sections were photographed and analyzed using ImageJ software. Superficial laminae I/II of the spinal dorsal horn were outlined and measured (in pixels). Area and the number of immunoreactive neuronal nuclei for c-Fos in this region were counted. For every section the number of labeled neurons per measured area ratio was calculated. Cells/area (c/a) ratios were averaged for each slice and eight to sixteen slices from different rats were included in each experimental group. The data are represented as mean \pm SEM. The difference between the groups was compared using One Way ANOVA followed by HolmSidak post hoc test (SigmaStat ${ }^{\circledR}$ software), the criterion for statistical significance was $P<0.05$.

To test the effect of PAC treatment on neuronal activation we measured the number of c-Fos-positive cells in the lumbar spinal cord slices. Our experiments showed that incubation for $1 \mathrm{~h}$ with $100 \mathrm{nM}$ PAC increased significantly the number of c-Fos immunoreactive neurons in laminae $\mathrm{I} / \mathrm{II}$ of the dorsal horn (Fig. 1; 2A, B, $P<0.001$ ). Pre-incubation with TRPV1 receptor antagonists in both experiments SB366791 (Fig. 2A, SB+PAC, $P<0.01$ ) and AMG9810 (Fig. 2B, AMG + PAC,$\quad P<0.01) \quad$ significantly suppressed the PAC-induced c-Fos protein expression. The treatment with the AMG9810 alone, did not show any significant changes in the number of c-Fos expressing dorsal horn neurons from the CTRL group, while incubation with only SB366791 induced a minor increase in the c-Fos expression (Fig. 2A, SB, $P<0.05$ ).

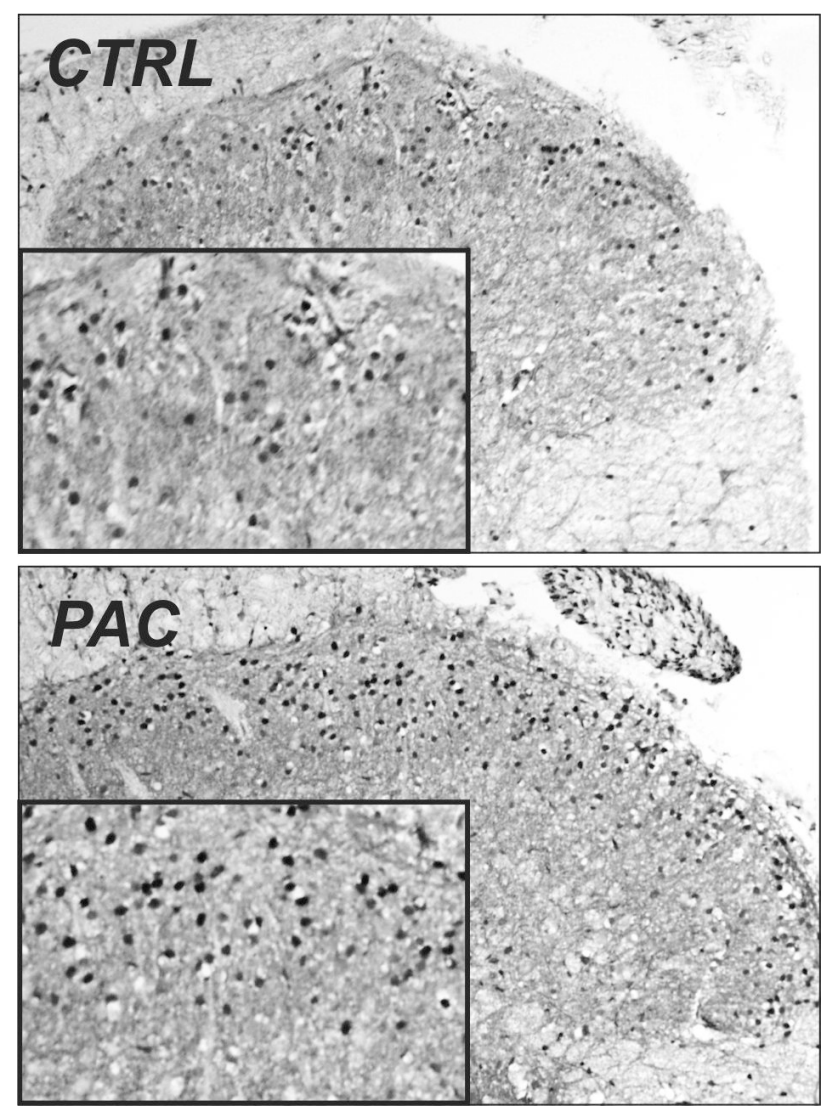

Fig. 1. Paclitaxel-induced upregulation of c-Fos expression in neuronal nuclei in the superficial area of spinal cord dorsal horn. Acute spinal cord slices were incubated with vehicle (CTRL) or with $100 \mathrm{nM}$ paclitaxel (PAC). Inserts demonstrate c-Fos positive neuronal nuclei in the same slices at higher magnification. 
A number of studies confirmed a wide diversity of peripheral stimuli that trigger upregulation of the immediate early gene $c$-Fos and its protein product c-Fos in dorsal horn neurons (Coggeshall 2005). However, in our in vitro study only central branches of primary afferents were present and thus the effect of PAC on spinal dorsal horn neurons had to be either due to the activation of presynaptic endings and/or due to action on the postsynaptic neurons. Recently it was shown that systemic administration of paclitaxel leads to thermal hypersensitivity and increased expression of TRPV1 receptors in DRG neurons (Hara et al. 2013). It was also documented (Li et al. 2015) that TRPV1 and TLR4 receptors are co-expressed in DRG neurons, intrathecal application of TRPV1 antagonist attenuated PAC-induced hypersensitivity and increase of TRPV1 expressing DRG neurons after PAC treatment was dependent on activation of Toll-like receptors 4 (TLR4). Additionally, PAC treatment increased TRPV1 receptors responsiveness to capsaicin also through TLR4 dependent pathway (Li et al. 2015). These findings suggest that in our study increase in c-Fos expression was mainly due to activation of presynaptic TLR4 and TRPV1 receptors. Activation of TLR4 receptors may beside others trigger c-Fos gene activation directly (Introna et al. 1986, Guha and Mackman 2001). However, in the spinal cord, TLR4 receptors are expressed predominantly in glial cells (Saito et al. 2010, Li et al. 2014) but not neurons (Li et al. 2014). Microglial activation could lead to release of cytokines and chemokines (Saito et al. 2010), potentiating presynaptic TRPV1 receptors function (Spicarova et al. 2011, Spicarova et al. 2014a). The effect of PAC treatment in this study was thus most likely mediated through presynaptic and/or glial TLR4 receptors followed by activation of presynaptic TRPV1 receptors, which led to increased release of neurotransmitters and neuromodulators such as glutamate, substance-P and calcitonin gene related peptide (CGRP) followed by activation of postsynaptic neurons and c-Fos expression. This is in agreement with increased spontaneous and miniature excitatory postsynaptic currents frequency after PAC treatment that was dependent on TRPV1 receptors activation in similar in vitro conditions ( $\mathrm{Li}$ et al. 2015). While the effect of the TRPV1 antagonists in our experiments with c-Fos expression after low $(100 \mathrm{nM})$ PAC treatment was robust, it is clear that other mechanisms play a role in the process (Boyette-Davis et al. 2015). Activation of protease activated receptor 2 (PAR2) and subsequently of protein kinases $\mathrm{A}, \mathrm{C}$ and phospholipase $\mathrm{C}$ and sensitization of TRPV1, TRPV4 and TRP ankyrin 1 (TRPA1) was demonstrated to be important for PIPN pain development (Chen et al. 2011). High concentration $(50 \mu \mathrm{M})$ PAC applied on esophagus slices induced CGRP release that was prevented by capsaicin induced desensitization and was reduced by TRPA1 and TRPV4 antagonists that also reduced mechanical allodynia present after systemic PAC treatment (Materazzi et al. 2012). In our experiments, both antagonists significantly diminished the PAC-induced c-Fos expression. However, application of SB366791 alone, but not AMG9810, induced a modest but still significant increase in c-Fos expression, when compared to the control group. This was most likely due to unspecific effect, while the two antagonists used exhibit different functional properties (Gavva et al. 2005).
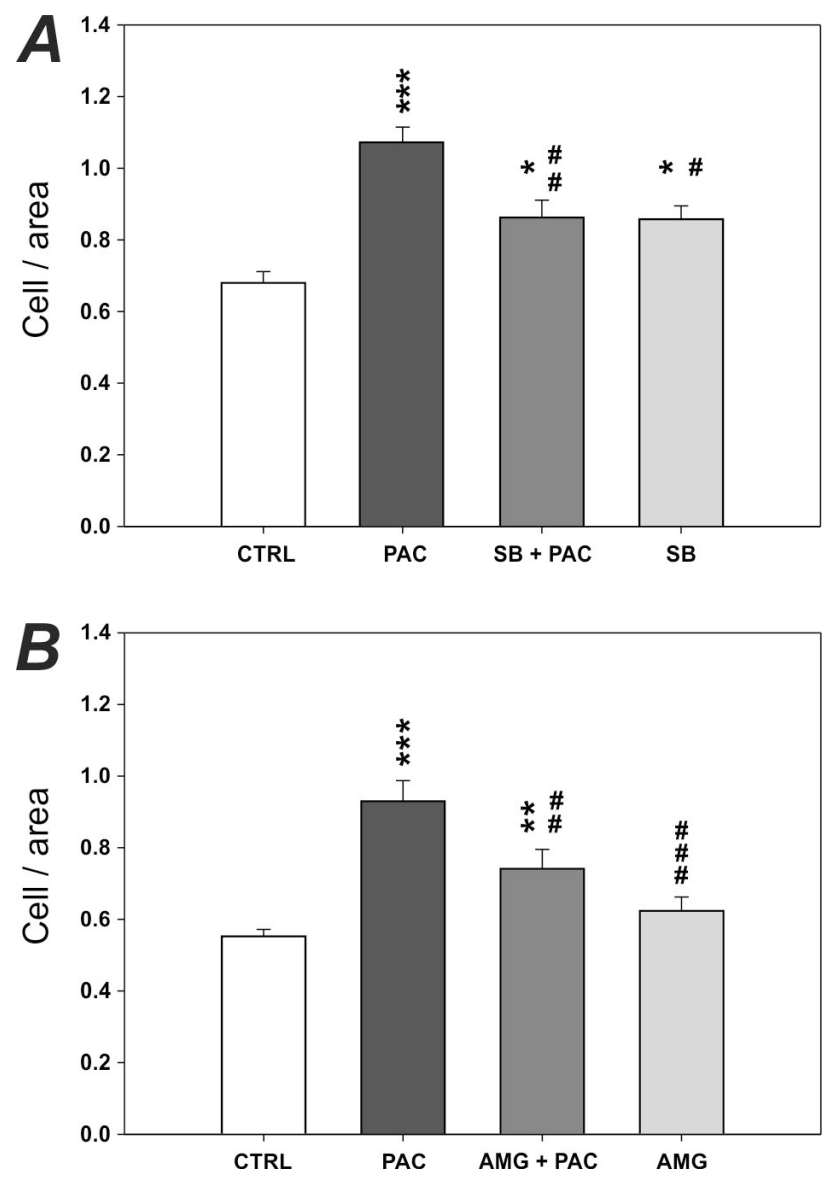

Fig. 2. The number of c-Fos-positive cells in the superficial spinal cord dorsal horn in controls (CTRL), after paclitaxel treatment (PAC), with TRPV1 antagonists added (SB+PAC; AMG+PAC) and TRPV1 antagonists only (SB; AMG). Data are presented as means \pm SEM. Asterisks indicate significant difference from the control group (One Way ANOVA, Holm-Sidak post hoc test, $* P<0.05$; ** $P<0.01 ; * * * P<0.001)$. Hashtags indicate significant difference from the PAC group (One Way ANOVA, Holm-Sidak post hoc test, \# $P<0.05$; \#\# $P<0.01$; \#\# $P<0.001)$. 
Our results showed that incubation of spinal cord slices in vitro with low concentration PAC induced c-Fos expression in dorsal horn neurons that was diminished by pre-treatment with TRPV1 antagonists. These findings further document the role of spinal cord TRPV1 receptors in the development of pathological pain states, including neuropathic pain after paclitaxel treatment.

\section{Conflict of Interest}

There is no conflict of interest.

\section{Acknowledgements}

This work was supported by the following grants: GACR 15-11138S; GAUK 1566314; MSMT LH15279; RVO 67985823; BIOCEV CZ.1.05/1.1.00/02.0109.

\section{References}

BOYETTE-DAVIS JA, WALTERS ET, DOUGHERTHY PM. Mechanisms involved in the development of chemotherapy-induced neuropathy. Pain Manag 5: 285-296, 2015.

CHEN Y, YANG C, WANG ZJ. Proteinase-activated receptor 2 sensitizes transient receptor potential vanilloid 1, transient receptor potential vanilloid 4 , and transient receptor potential ankyrin 1 in paclitaxel-induced neuropathic pain. Neuroscience 193: 440-451, 2011.

COGGESHALL RE: Fos, nociception and the dorsal horn. Prog Neurobiol 77: 299-352, 2005.

CUI M, GOSU V, BASITH S, HONG S, CHOI S: Polymodal transient receptor potential vanilloid type 1 nocisensor: structure, modulators, and therapeutic applications. Adv Protein Chem Struct Biol 104: 81-125, 2016.

GAVVA NR, TAMIR R, KLIONSKY L, NORMAN MH, LOUIS JC, WILD KD, TREANOR JJ: Proton activation does not alter antagonist interaction with the capsaicin-binding pocket of TRPV1. Mol Pharmacol 68: 1524-1533, 2005.

GUHA M, MACKMAN N: LPS induction of gene expression in human monocytes. Cell Signal 13: 85-94, 2001.

HARA T, CHIBA T, ABE K, MAKABE A, IKENO S, KAWAKAMI K, UTSUNOMIYA I, HAMA T, TAGUCHI K: Effect of paclitaxel on transient receptor potential vanilloid 1 in rat dorsal root ganglion. Pain 154: 882-889, 2013.

HUNT SP, PINI A, EVAN G: Induction of c-fos-like protein in spinal cord neurons following sensory stimulation. Nature 328: 632-634, 1987.

INTRONA M, HAMILTON TA, KAUFMAN RE, ADAMS DO, BAST RC JR: Treatment of murine peritoneal macrophages with bacterial lipopolysaccharide alters expression of c-fos and c-myc oncogenes. $J$ Immunol 137 : 2711-2715, 1986.

LI Y, ADAMEK P, ZHANG H, TATSUI CE, RHINES LD, MROZKOVA P, LI Q, KOSTURAKIS AK, CASSIDY RM, HARRISON DS, ET AL.: The cancer chemotherapeutic paclitaxel increases human and rodent sensory neuron responses to TRPV1 by activation of TLR4. J Neurosci 35: 13487-13500, 2015.

LI Y, ZHANG H, KOSTURAKIS AK, JAWAD AB, DOUGHERTY PM: Toll-like receptor 4 signaling contributes to Paclitaxel-induced peripheral neuropathy. J Pain 15: 712-725, 2014.

MATERAZZI S, FUSI C, BENEMEI S, PEDRETTI P, PATACCHINI R, NILIUS B, PRENEN J, CREMINON C, GEPPETTI P, NASSINI R. TRPA1 and TRPV4 mediate paclitaxel-induced peripheral neuropathy in mice via a glutathione-sensitive mechanism. Pflugers Arch 463: 561-569, 2012.

NAGY I, FRISTON D, VALENTE JS, TORRES PEREZ JV, ANDREOU AP: Pharmacology of the capsaicin receptor, transient receptor potential vanilloid type-1 ion channel. Prog Drug Res 68: 39-76, 2014.

SAITO O, SVENSSON CI, BUCZYNSKI MW, WEGNER K, HUA XY, CODELUPPI S, SCHALOSKE RH, DEEMS RA, DENNIS EA, YAKSH TL: Spinal glial TLR4-mediated nociception and production of prostaglandin E(2) and TNF. Br J Pharmacol 160: 1754-1764, 2010.

SPICAROVA D, ADAMEK P, KALYNOVSKA N, MROZKOVA P, PALECEK J: TRPV1 receptor inhibition decreases CCL2-induced hyperalgesia. Neuropharmacology 81: 75-84, 2014a.

SPICAROVA D, NERANDZIC V, PALECEK J: Modulation of spinal cord synaptic activity by tumor necrosis factor alpha in a model of peripheral neuropathy. J Neuroinflammation 8: 177, 2011.

SPICAROVA D, NERANDZIC V, PALECEK J: Update on the role of spinal cord TRPV1 receptors in pain modulation. Physiol Res 63 (Suppl 1): S225-S236, 2014b.

YAN X, MAIXNER DW, YADAV R, GAO M, LI P, BARTLETT MG, WENG HR: Paclitaxel induces acute pain via directly activating toll like receptor 4. Mol Pain 11: 10, 2015. 